Article

\title{
Fierce Heat and Players' Health: Examining the View on Japan High School Baseball
}

\author{
Eiji Yamamura ${ }^{1, *}$ \\ 1 Department of Economics, Seinan Gakuin University, Fukuoka 814-8511, Japan \\ * Correspondence: yamaei@seinan-gu.ac.jp \\ Received: ${ }^{* * *}$ Nov 2021; Accepted: ${ }^{* * * * *}$ 2021; Published: date
}

\begin{abstract}
A summer high school baseball tournament is held every mid-summer in Koshien Stadium. "Koshien Baseball" is very popular in Japan; however, it faces the problem of extremely high temperatures during games. Thus, high school players are threatened by the harsh environment. For this reason, Internet surveys were conducted twice to purposefully engage the same individuals. Then, information on their views regarding the Koshien tournament before and after the provision of information regarding environmental change in Japan was gathered. Using data, this study examined how their views changed after having the information. Compared with the view before, it was found that (1) respondents were more likely to agree that the management rule of the Koshien tournaments should be altered to protect player's health, and (2) the impact of providing information is larger for female respondents, young people, and highly educated respondents.
\end{abstract}

Keywords: High school baseball; Health; Heatwave; Heatstroke; Sustainability; Environment; Gender difference; Japan

\section{Introduction}

The average temperature in Japan rises every year. Particularly, during mid-summer, the thermometer frequently recorded temperatures greater than $35^{\circ} \mathrm{C}$ accompanied by high humidity. Due to climate change, the lives of Japanese people became jeopardized. Thus, during the final week of July 2019, a total of 5,600 people were sent to the hospital because of heatstroke [1]. Furthermore, in the summer of 2019, a total of 162 people died of heatstroke during heatwaves [2]. During the summer 2020 Tokyo Olympics, the players experienced serious heatwaves accompanied by high humidity. For example, during the match, a tennis player Daniil Medvedev told the chair umpire, "I can finish the match, but I can also die" and asked him "If I die, are you going to be responsible?" [3]. By 2085, most cities in the Northern Hemisphere would be too risky to hold the summer Olympics because of environmental changes [4].

Baseball is one of the most popular sports in Japan. The Japanese are attracted not only to professional baseball games but also to amateur ones. During the annual spring and summer seasons in Japan, the national high school baseball tournament is held annually at the Kōshien Stadium in summer and spring. In the summer tournament, 49 teams were selected to represent 47 prefectures and play games in Koshien Stadium, while in the spring, only 30 teams were selected to play. The summer "Koshien Baseball" is larger than the one in spring, and it is the most popular sports event in Japan [4-6]. The high 
school summer break usually begins on July 20 and ends on August 31, although there are some differences among prefectures. During the summer high school break, games for regional elimination and main Koshien tournament games are held. In other words, the final game of Koshien must be completed before entering September when high school reopens. Inevitably, the schedule is very tight. During the Koshien tournament, there are four games every day, except the days when the final or semi-final games are held. Koshien is an open-air stadium. "As hot as the action can be on the field, the soaring temperatures during the day can be dangerous for fans watching the games. . . Amid the relentless heatwave, shops at the stadium began selling portable electric fans, cooling mist spray bottles, and other items as part of efforts to prevent the crowd from suffering heatstroke"[8]. However, high school boys play under a scorching sun and high humidity. They are exhausted and face the risk of heatstroke. The Japan High School Baseball Federation ( JHBF) has faced considerable difficulty in arranging optimal conditions for games to protect players. Several measures have been adopted to address this problem. For instance, the JHBF pushed back the starting times of two quarterfinal games to avoid the hottest times of the day. One game started at 7 p.m. and did not end until approximately 11 p.m. [9]. However, the problem has not been solved substantially because most games take place mid-day because of the tight schedule.

The problem of the Koshien tournament has drawn attention in Japan [8]-[10]. However, the summer Koshien Tournament started in 1915, when 15 years before, Uruguay won soccer's first World Cup [7]. That is, for over 100 years, high school boys played during mid-summer. The history and experience of the Koshien tournament led people to have a conservative view to keep the current system and rule. However, negative effects of heatwaves on society have been widely observed in previous studies [12]-[18]. For instance, a heatwave was accompanied by large excess mortality [14]. Thermoelectric power plants depend on cooling water. High water temperatures limit a plant's production capacity, leading to an increase in cost and electricity price [18]. Furthermore, high temperatures reduce workers' incentive to work [19] and reduce productivity [20].

It is unknown whether people who adhere to the traditional system of the Koshien tournament consider climate change during the past 100 years. Increasingly, various studies have conducted information provision experiments and found that people's behavior changed after the information was provided [21]-[26]. There was a moderate reduction in partisan differences in beliefs regarding climate change if survey respondents were provided with incentives [27]. It is worth analyzing how information provision gives people an incentive to improve the situation to sustain society. Through an Internet experiment, this study examined how and to what extent people's views about the Koshien tournament changed by providing information on climate change in Japan. The key findings were that respondents are more likely to agree that the management rule should be changed to protect the player's health after providing the information. Furthermore, the effect was greater for female, young, and highly educated respondents.

The remainder of this paper is organized as follows: Section 2 describes the research design and data. Section 3 presents the results and interpretations. Section 4 discusses the study findings. The final section provides reflections and conclusions.

\section{Methods and data}




\subsection{Experimental design}

A flowchart of the simple experiment used in this study is presented in Figure 1. As explained further in the text, the same respondents participated in the first and follow-up surveys to answer the same questions regarding the system of the Koshien Tournament. The difference is that respondents were informed of the rise of extreme heat days in the follow-up survey. Therefore, the effect of information provision was examined in the experimental design.

\subsubsection{First Survey}

In Japan, the Nikkei Research Company ( NRC) has experience in academic research on Internet surveys [28]-[30]. Therefore, the NRC was commissioned to conduct a nationally representative web survey throughout Japan on October 25-30th, 2018. A total of 9,130 participants participated in the survey. In the first survey, 7,855 observations were gathered, which were reduced to 7,285 in the follow-up survey. Eventually, the response rate reached $79 \%$. In the first survey, as basic information, respondents were asked about residential locality, their age, and educational background, and they were selected from 47 prefectures. They were then asked to report their subjective views about the Koshien tournament:

Do you agree that the operation system of the tournament should be changed to protect the school player's health?

1 (Strongly disagree) to 5 (Strongly agree).

\subsubsection{Follow-up Survey}

Two weeks after the first survey, the second follow-up survey was distributed to the respondents who completed the questionnaire the first time. Hence, the two-period panel data were constructed through the first and follow-up surveys. As per the flow chart shown in Figure 1, information on climate change was provided directly before they answered the question about the Koshien Tournament. The specific information of climate changes is demonstrated in Figure 2, where we indicate the total number of extreme heat days every five years during-1880-2015. An extreme heat day was defined as having a temperature $>35^{\circ} \mathrm{C}$. However, the temperature varies according to the location where the temperature was measured. Therefore, we used the data for extremely hot days in Osaka because Osaka is near and has a climate similar to that of Koshien Stadium. 


\section{The first survey}

Respondent's answer questions of basic characteristics and the KOSHIEN tournament.
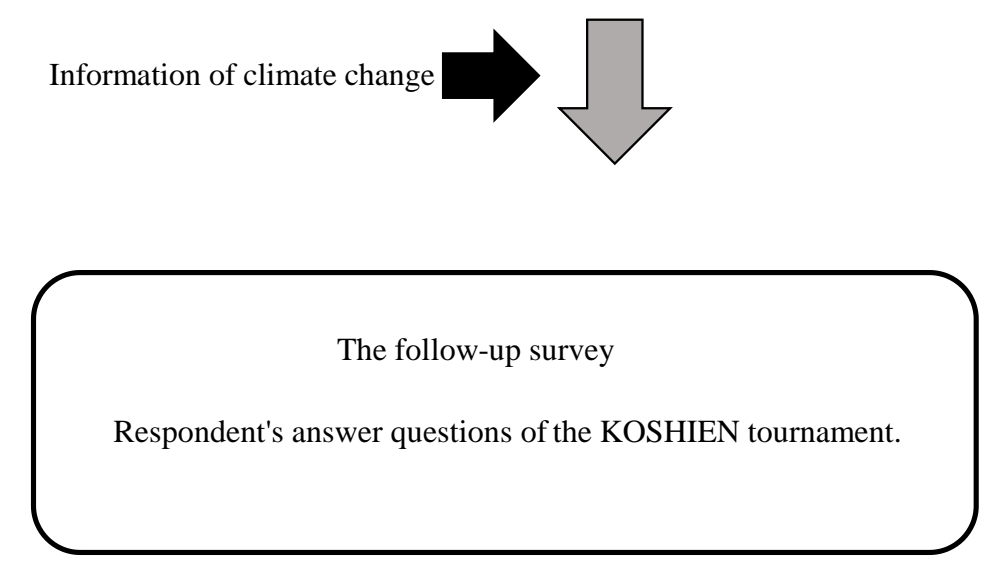

Figure1. Flow-chart of the Internet experiment

Cursory examination of Figure 2 reveals that the total number of extreme heat days was $<5$ days for five years, and so people averagely experienced extreme heat days once every two or three years. After World War II, we observed an increasing trend, although there was a wide variation. In particular, it is noteworthy that the number of extremely hot days increased drastically after the 1990s and reached 35 days in 2015. That is, on average, people living in Osaka experienced seven days with temperatures exceeding $35^{\circ} \mathrm{C}$. Furthermore, the hottest season is during the Koshien Tournament. Furthermore, most of the games in the Koshien Tournament were conducted during the daytime. Figure 2 implies that high school players face the risk of heatstroke, especially after entering 2000.

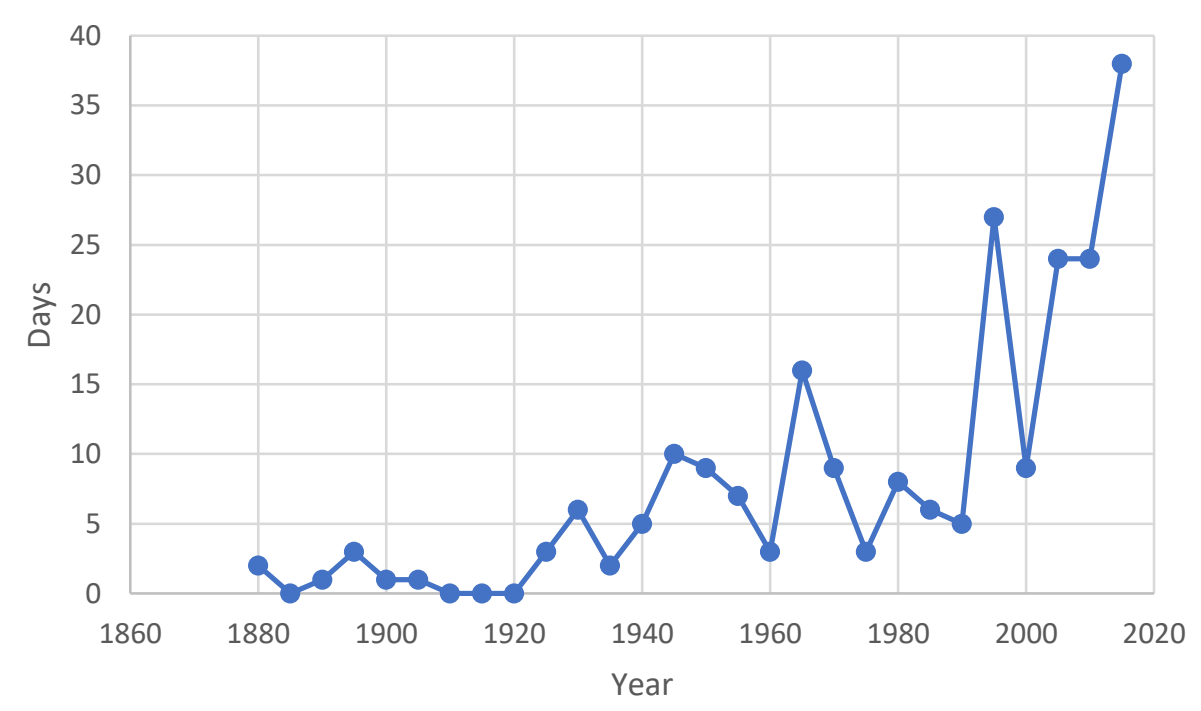

Figure 2. Total number of extremely hot days in October at Osaka (Japan) every five years, in the period 1880-2015.

Note: An extremely hot day is defined when the temperature exceeds $35^{\circ} \mathrm{C}$.

Source: Website of Japan Meteorological Agency. http://www.data.jma.go.jp/risk/obsdl/index.php (Accessed on 23 August 2018). 


\subsection{Data}

Using data obtained from the Internet experiment described in Section 2.1., this paper conducts an experiment on how people's views about the Koshien tournament games changed after having the information of an increase in the day with the temperature exceeding $35^{\circ} \mathrm{C}$ from 1880 to 2015 .

Table 1. Description of variables and its means and standard deviation.

\begin{tabular}{llcc}
\hline & \multicolumn{1}{c}{ Description } & Mean & s.d. \\
\hline KOSHIEN & $\begin{array}{l}\text { Do you agree that the operation system of the } \\
\text { tournament should be changed to protect the school } \\
\text { player's health.? } \\
\text { 1 (strongly disagree)-5 (strongly agree) }\end{array}$ & 3.58 & 1.00 \\
\hline INFORMATION & $\begin{array}{l}\text { Equals 1 if the information of climate change is } \\
\text { provided, 0 otherwise. }\end{array}$ & 0.50 & 0.50 \\
\hline UNIV & $\begin{array}{l}\text { Equals 1 if respondents graduated from university, 0 } \\
\text { otherwise. }\end{array}$ & 0.25 & 0.43 \\
\hline YOUNG_AGE & $\begin{array}{l}\text { Equals 1 if respondents are younger than 30 years old, } \\
\text { 0 otherwise. }\end{array}$ & 0.18 & 0.38 \\
\hline FEMALE & Equals 1 if respondents are women, 0 otherwise & 0.49 & 0.50 \\
\hline Observations & & 14,570 & \\
\hline
\end{tabular}

Note: The samples before and after providing the information are included. Information on climate change was provided to all respondents. INFORMATION is equivalent to the follow-up survey dummy, which equals 1 if data is from the follow-up survey, and 0 otherwise.

Table 1 describes the variables and their mean values and standard errors using the sample before and after the provision of the information. KOSHIEN is a discrete variable ranging from 1 (strongly disagree) to 5 (strongly agree). The mean value of KOSHIEN is 3.58 on a 5-point Likert-type scale. None of the respondents had any information in the first survey and then obtained the information in the follow-up survey. This is reflected in the mean value of INFORMATION at 0.50 . The mean value of $U N I V$ is 0.25 , suggesting that $25 \%$ of the respondents graduated from university. YOUNG_AGE is 0.18 , indicating that $18 \%$ of the respondents were younger than 30 years. The mean value of $F E M A L E$ was 0.49 , indicating that almost half of the respondents were women. This implies that respondents prefer the tournament system on average.

For a closer examination of KOSHIEN, Figure 1 illustrates the distribution of KOSHIEN by dividing it into sub-samples before and after providing the information. There was a striking difference in their distribution. Before providing the information, approximately $40 \%$ of respondents chose " 3 " and so were neutral for the question. Respondents who selected "Agree" or "Strongly agree" were about $30 \%$ and $20 \%$. After providing the information, respondents who selected neutral declined to slightly lower than 30 , while respondents who selected "Strongly agree" rose to slightly over $30 \%$. As a whole, many respondents were more likely to support changes in the system after obtaining the information. 


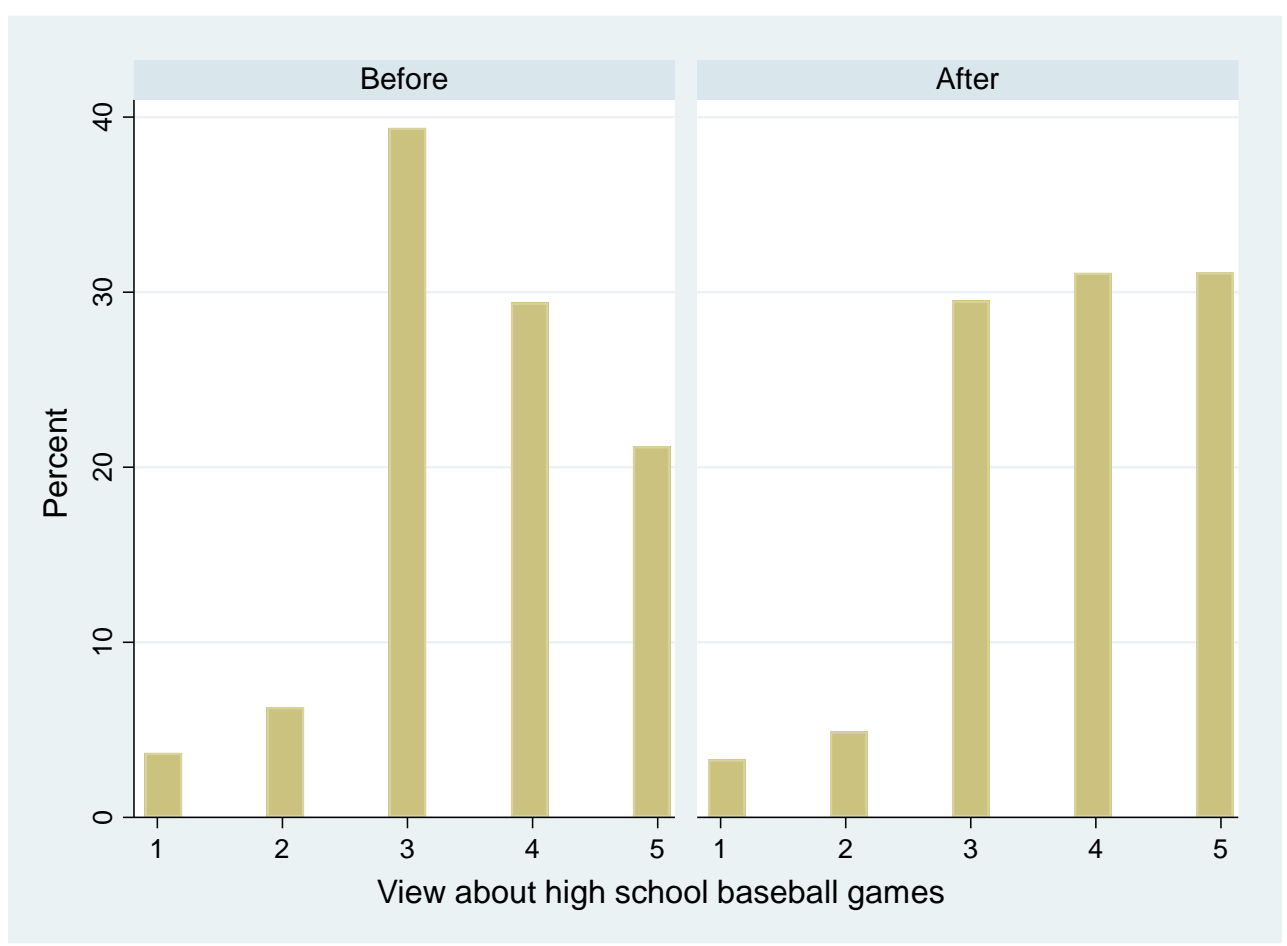

Figure 3. Distribution of view about the Koshien baseball tournament before and after provision of information.

\subsection{Method}

Here, the effect of providing information on climate change from the perspective of the tournament system is provided. A fixed-effects model was conducted. The baseline estimated function took the following form:

$$
\text { KOSHIEN }_{i t}=\alpha_{0}+\alpha_{1} \text { INFORMATION }_{t}+m_{i}+u_{i t}
$$

where KOSHIEN it represents the dependent variable for individual $i$ and time point $t$. The regression parameters are denoted as $\alpha$. The error term is denoted by $u$. The key independent variable was FORMATION. The sign of the coefficient of INFORMATION is expected to be positive if the information on increasing extreme heat days leads respondents to agree with the change in the tournament system.

Furthermore, it was explored how the effect of information varies according to the respondent characteristics. For this purpose, several cross terms with INFORMATION were included in the alternative specifications.

INFORMATION*FEMALE, INFORMATION*YOUNG_AGE and INFORMATION*UNIV.

Various studies suggest that there are sex differences regarding risk and overconfidence. Women are more likely to exhibit risk aversion and be cautious [31]-[33]. They are also more benevolent and universally concerned[33]. From this, we infer that women are more likely to agree with the change in the tournament system to protect the health of high school boys. Hence, the predicted sign of the coefficient of INFORMATION*FEMALE is positive. The status quo bias is that people tend to do nothing or maintain their current or previous decisions, even if it is better to change their decisions[34]-[36]. Young people are less likely to have status-quo biases[34]-[37]. Accordingly, people are more willing to change the existing traditional tournament system. Hence, the predicted sign of the coefficient of INFORMATION* YOUNG_AGE is positive. Turning to INFORMATION*UNIV, more educated people are more able to appropriately evaluate the effect of heatwaves on players' health after knowing the real situation of increasing extreme heat days. Thus, the coefficient of INFORMATION* UNIV is predicted to have a positive sign. 


\section{Results}

In Table 2, the estimates obtained from the fixed effects (EF) estimations are presented. This table indicates a positive sign for INFORMATION and statistical significance at the $1 \%$ level in all columns, thus supporting the inference presented in the previous section. In column (1), the absolute value of the INFORMATION coefficient is 0.234 . This implies that providing the information caused respondents to agree with the change in the tournament system by a 0.234 point on a 5 -point scale.

Turning to column (2), the sign of INFORMATION*FEMALE is positive and statistically significant at the $1 \%$ level, which is consistent with the inference in the previous section. The absolute value is 0.098 , meaning that the effect of providing information for women is 0.098 points larger than that for men. The coefficient of INFORMATION is 0.187 , meaning that the effect of information provision for men is 0.187 points. Based on these results, the information provision effect for women was $52 \%$ greater than that for men.

As for column (3), the sign of INFORMATION*YOUNG_AGE is positive and statistically significant at the $1 \%$ level, which is consistent with the inference in the previous section. The absolute value is 0.077 , implying that the effect of providing information for people below 30 years of age is 0.077 points larger than for people over 30 years of age. The coefficient of INFORMATION is 0.221 , suggesting that the effect of information provision for older people is 0.221 points. Considering jointly, the information provision effect for young people is 35\% larger than that for older people.

In column (4), the sign of INFORMATION*UNIV shows a positive sign and statistical significance at the $5 \%$ level. This is in line with the inference presented in the previous section. The absolute value is 0.047 , indicating that the effect of providing information for those who graduated from university is 0.047 points greater than that of lower-educated people. The coefficient of INFORMATION is 0.223 , suggesting that the effect of information provision for low-educated people is 0.223 points. Overall, the information provision effect for educated people is $21 \%$ greater than that for low-educated people.

The results jointly reveal that the predicted effect of information provision is more strongly observed for female, young, and highly educated people. However, the effect is also observed for men, old, and low-educated people, although its effect is smaller.

Table 2. Estimation results of the FE model (dependent variable is "KOSHIEN")

\begin{tabular}{|c|c|c|c|c|}
\hline \multicolumn{5}{|c|}{ KOSHIEN } \\
\hline & (1) & (2) & (3) & (4) \\
\hline \multirow[t]{2}{*}{ INFORMATION } & $0.234^{* * *}$ & $0.187^{* * *}$ & $0.221^{* * *}$ & $0.223^{* * *}$ \\
\hline & $(0.01)$ & $(0.02)$ & $(0.02)$ & $(0.01)$ \\
\hline \multirow{2}{*}{$\begin{array}{l}\text { INFORMATION } \\
{ }^{*} F E M A L E\end{array}$} & & $0.098^{* * *}$ & & \\
\hline & & $(0.02)$ & & \\
\hline \multirow{2}{*}{$\begin{array}{c}\text { INFORMATION } \\
{ }^{*} \text { YOUNG AGE }\end{array}$} & & & $0.077^{* *}$ & \\
\hline & & & $(0.03)$ & \\
\hline \multirow{2}{*}{$\begin{array}{l}\text { INFORMATION } \\
\text { *UNIV }\end{array}$} & & & & $0.047^{* *}$ \\
\hline & & & & $(0.02)$ \\
\hline Within R-squared & 0.06 & 0.06 & 0.08 & 0.08 \\
\hline Observations & 14,570 & 14,570 & 14,570 & 14,570 \\
\hline
\end{tabular}

Note: Numbers within parentheses are robust standard errors clustered by individuals. ${ }^{* * *} p<0.01,{ }^{* *}$ $p<0.05,{ }^{*}$ and $p<0.1$. 


\section{Discussion}

From the study findings, it follows that information on climate change is effective in directing people to change the tournament system to protect players' health and thus make the tournament sustainable. Japanese people are likely to know through their experience that the average temperature rises. However, they are unlikely to connect climate change with summer sports and players' health. Therefore, responses to questions about tournament systems change if they are asked directly after providing the information. Further, Japanese people's perception about the rise in heat waves is possibly reinforced by the provision of objective information, such as the rising trend exhibited in Figure. One idea is to solve the problem substantially by changing the stadium from Koshien to a roofed baseball park, called an all-weather baseball stadium.

The findings of this study made it evident that women are more sensitive to objective information about climate change than men. Compared to men, women tend to be more benevolent and universally concerned [33], which leads to paying attention to the health condition of sports players. Through social interaction, women's responses influence men, which direct surrounding men to have a more positive view of activity in a sustainable society [29]. Similarly, the effect of information provision is larger for highly educated and young people when they consider the relation between heat waves and health. People can adapt to the risk of heatwaves by learning past experiences [14]. The learning effect on disaster prevention can be strengthened through social interaction [38]. Hence, first, the provision of information should be more intensively provided to women, highly educated, and young people. Then, spillover through social interaction generates the norm, which changes the view of men, low-educated, and older people.

In addition to health [14], the issue of temperature change can be considered in terms of productivity. The heatwave reduces the quality of play in the baseball game. An increase in temperature has a detrimental effect not only on agricultural productivity[39], but also on manufacturing labor productivity [35], [36], and years of high temperatures are associated with lower economic output in developing countries, which can be explained by reduced worker productivity and increased absenteeism on hot days[19]. High temperatures $>21^{\circ} \mathrm{C}$ lead to drops in online game performance [40]. Online gaming requires intense engagement and the deployment of cognitive skills, which are key factors in other productive activities. Temperature anomalies at the time of birth have long-term negative impacts on individuals' economic productivity after they become adults, implying that human capital formation is hampered [41]. Climate control is considered to significantly mitigate productivity losses in various sectors.

Provision of information about an increase in heat days plays a critical role in changing the social system to protect workers' health and to maintain their engagement in work and their productivity. This is the key to achieving sustainable development.

\section{Conclusions}

Extremely high temperatures have negative effects on labor productivity and health conditions. During the 2020 Tokyo Olympics games, players experienced heatwaves, which led them to encounter difficulties. Athletes struggled with the heat accompanied by high humidity during games, and some of them experienced serious injuries falling unconscious[42]. Actually, under the same conditions. Summer high school baseball tournaments have been held every mid-summer for over 100 years since 1915 . The traditional tournament system has not been modified, although the number of extremely hot days has increased. This leads high school players to be endangered by bad environments. Internet surveys were conducted twice to purposefully pursue the same individuals. Then, the view of changing the tournament system before and after providing the information was compared. Using the data, it was found that compared with the view before, respondents were more likely to agree that the management rule of the Koshien tournaments should be changed to protect player's health, and (2) the effect was greater for female respondents, young people, and highly educated respondents. However, the provision substantially changed views for men, old people, and 
low-educated people. Through social interaction, the tournament system would change if people are provided with the correct information about climate change.

Author Contributions: E.Y. contributed to the conception, analysis, interpretation of data, and writing of the article.

Funding: This research was funded by the Japan Society for the Promotion of Science (grant number [16H03628]).

Institutional Review Board Statement: Ethical review and approval were waived for this study. The survey used in this study falls outside the scope of the Japanese government's Ethical Guidelines for Medical and Health Research Involving Human Subjects, and there are no national guidelines in Japan for social and behavioral research. Therefore, our study was carried out in accordance with the Ethical Principles for Sociological Research of the Japan Sociological Society, which does not require an ethical review.

Informed consent statement: Informed consent was obtained from all subjects involved in the study. All survey participants gave their consent to participate in the anonymous online survey by the Nikkei Research Company. The authors did not obtain personal information about the participants. After being informed about the purpose of the study and their right to quit the survey, participants agreed to participate. They were provided with the option "I do not want to respond. The completion of the entire questionnaire was considered to indicate the participants' consent.

Data Availability Statement: The data presented in this study are available upon request from the corresponding author.

Acknowledgments: We would like to thank Editage (http://www.editage.com) for editing and reviewing this manuscript for the English language.

Conflicts of Interest: The authors declare that there is no conflict of interest.

\section{References}

[1] Kyodo News, "11 dead, 5,600 people sent to hospitals in Japan heatwave," Kyodo News, Jul. 30, 2019.

[2] I. Ando, A. Takeuchi, and S. Araki, "Japan heatstroke death toll hits 162; lack of air conditioning cited," Mainichi Newspaper, Aug. 10, 2019.

[3] A. Durkee, "Tokyo Olympics: Tennis shifts later due to extreme heat after player Medvedev says he 'can die' during match," Forbs, Jul. 28, 2021.

[4] K. R. Smith et al., "The last Summer Olympics? Climate change, health, and work outdoors," The Lancet, vol. 388, no. 10045. Lancet Publishing Group, pp. 642-644, Aug. 13, 2016. doi: 10.1016/S0140-6736(16)31335-6.

[5] E. Yamamura, "Identity, nostalgia and happiness among migrants: The case of the Kōshien High School Baseball Tournament in Japan,” Pacific Economic Review, 2017, doi: 10.1111/1468-0106.12226.

[6] R. WHITING, "Agony and ecstasy: Why Japan is obsessed with high school baseball," Nikkei Asia, Jul. 24, 2019.

[7] B. Lefton, "In Japan, 100 Years of Glory Days for High School Baseball," New York Times (Online), Aug. 16, 2018.

[8] Yomiuri Newspaper, "Fans at Koshien finding ways to beat the heat Baseball Federation of JAPAN ," Yomiuri Newspaper, Aug. 12, 2019.

[9] M. Rich, H. Ueno, and M. Inoue, "In Japan, Deadly Heat Wave Tests Endurance of Even the Most Stoic," New York Times (Online), Jul. 25, 2018. 
[10] R. Arai, T. Fujita, and M. Yasuda, "Japan Koshien HS ballplayers using white spikes to counter heat in substitute event," Mainichi Newspaper, Aug. 14, 2020.

[11] Yomiuri Newspaper, "Editorial: Use tiebreakers as 1st step to ease burden on high school baseball players," Yomiuri Newspaper, Sep. 25, 2017.

[12] A. Orlov, J. Sillmann, A. Aaheim, K. Aunanm, and K. Bruin, "Economic Losses of Heat-Induced Reductions in Outdoor Worker Productivity: a Case Study of Europe," Economics of Disasters and Climate Change, vol. 3, no. 3, pp. 191-211, 2019.

[13] S. Das, "Television Is More Effective in Bringing Behavioral Change: Evidence from Heat-Wave Awareness Campaign in India,” World Development, vol. 88, pp. 107-121, 2016.

[14] G. Rey, A. Fouillet, E. Jougla, and D. Hemon, "Heat Waves, Ordinary Temperature Fluctuations and Mortality in France since 1971," Population, vol. 62, no. 3, pp. $457-$ 485, 2007.

[15] P. Hota and B. Behera, "Understanding the Household Perceptions of and Adaptations to Heat Wave: A Case Study," International Journal of Ecological Economics and Statistics, vol. 33, pp. 98-117, 2014.

[16] R. Z. Zaidi and M. Pelling, "Institutionally Configured Risk: Assessing Urban Resilience and Disaster Risk Reduction to Heat Wave Risk in London," Urban Studies, vol. 52, no. 7, pp. 1218-1233, 2015.

[17] S. Das and S. C. Smith, "Awareness as an Adaptation Strategy for Reducing Mortality from Heat Waves: Evidence from a Disaster Risk Management Program in India," Climate Change Economics, vol. 3, no. 2, pp. 1-29, 2012.

[18] A. Pechan and K. Eisenack, "The impact of heat waves on electricity spot markets," Energy Economics, vol. 43, pp. 63-71, May 2014, doi: 10.1016/j.eneco.2014.02.006.

[19] E. Somanathan, R. Somanathan, A. Sudarshan, and M. Tewari, "The Impact of Temperature on Productivity and Labor Supply: Evidence from Indian Manufacturing," Journal of Political Economy, vol. 129, no. 6, 2021.

[20] X. Cai, Y. Lu, and J. Wang, "The impact of temperature on manufacturing worker productivity: Evidence from personnel data," Journal of Comparative Economics, vol. 46, no. 4, pp. 889-905, Dec. 2018, doi: 10.1016/j.jce.2018.06.003.

[21] I. Haaland, C. Roth, and J. Wohlfart, "Designing Information Provision Experiments," Journal of Economic Literature (Forthcoming), [Online]. Available: www.RePEc.org

[22] P. Dupas, "Do teenagers respond to HIV risk information? Evidence from a field experiment in Kenya," American Economic Journal: Applied Economics, vol. 3, no. 1, pp. 1-34, 2011, doi: DOI: 10.1257/app.3.1.1.

[23] L. Bennear, A. Tarozzi, A. Pfaff, S. Balasubramanya, K. M. Ahmed, and A. van Geen, "Impact of a randomized controlled trial in arsenic risk communication on household water-source choices in Bangladesh," Journal of Environmental Economics and Management, vol. 65, no. 2, pp. 225-240, 2013.

[24] H. Allcott and C. Knittel, "Are consumers poorly informed about fuel economy? Evidence from two experiments," American Economic Journal: Economic Policy, vol. 
11, no. $\quad 1, \quad$ pp. $1-37, \quad 2019, \quad$ doi: https://www.aeaweb.org/articles?id=10.1257/app.20170328.

[25] H. Allcott, "Social norms and energy conservation," Journal of Public Economics, vol. 95, no. 9-10, pp. 1082-1095, 2011, doi: https://mail.google.com/mail/u/0/?tab=wm\&ogbl\#inbox.

[26] T. Fetzer, L. Hensel, J. Hermle, and C. Roth, "Coronavirus Perceptions and Economic Anxiety," The Review of Economics and Statistics, pp. 1-36, Jun. 2020, doi: 10.1162/rest_a_00946.

[27] E. Peterson and S. Iyengar, "Partisan Gaps in Political Information and InformationSeeking Behavior: Motivated Reasoning or Cheerleading?," American Journal of Political Science, vol. 65, no. 1, pp. 133-147, Jan. 2021, doi: 10.1111/ajps.12535.

[28] E. Yamamura and Y. Tsutsui, "Trade policy preference, childhood sporting experience, and informal school curriculum: An examination of views of the TPP from the viewpoint of behavioral economics," Review of International Economics, vol. 27, no. 1, pp. 61-90, 2019.

[29] E. Yamamura, S. Managi, and Y. Tsutsui, "Male pupils taught by female homeroom teachers show a higher preference for Corporate Social Responsibility in adulthood," Journal of the Japanese and International Economies, vol. 54, p. 101048, 2019.

[30] A. Clark, C. Senik, and K. Yamada, "The Joneses in Japan: income comparisons and financial satisfaction," Japanese Economic Review.

[31] B. M. Barber and T. Odean, "Boys Will Be Boys: Gender, Overconfidence, and Common Stock Investment," Quarterly Journal of Economics, vol. 116, no. 1, pp. 261-292, 2001, doi: https://doi.org/10.1162/003355301556400.

[32] A. Beutel and M. Marini, "Gender and values," American Sociological Review, vol. 60, no. 3, pp. 436-448, 1995.

[33] R. Adams and P. Funk, "Beyond the glass ceiling: Does gender matter?," Management Science, vol. 58, no. 2, pp. 219-235, 2012.

[34] W. Samuelson and R. Zeckhauser, "Status Quo Bias in Decision Making," 1988.

[35] R. Fernandez and D. Rodrik, "Resistance to Reform: Status Quo Bias in the Presence of Individual- Specific Uncertainty," Amerian Economic Review, vol. 81, no. 5, pp. 1146-1155, 1991.

[36] D. Kahneman, J. L. Knetsch, and R. H. Thaler, "Anomalies The Endowment Effect, Loss Aversion, and Status Quo Bias," 1991.

[37] H. P. van DALEN, K. HENKENS, and D. A. HERSHEY, "Why do older adults avoid seeking financial advice? Adviser anxiety in the Netherlands," Ageing and Society, vol. 37, no. 6, pp. 1268-1290, Jul. 2017, doi: 10.1017/S0144686X16000222.

[38] E. Yamamura, "Effects of Interactions among Social Capital, Income and Learning from Experiences of Natural Disasters: A case study from Japan," Regional Studies, vol. 44, no. 8, pp. 1019-1032, 2010.

[39] R. Salim, K. Hassan, and S. Rahman, "Impact of R\&D expenditures, rainfall and temperature variations in agricultural productivity: empirical evidence from 
Bangladesh," Applied Economics, vol. 52, no. 27, pp. 2977-2990, Jun. 2020, doi: 10.1080/00036846.2019.1697422.

[40] X. Bao and Q. Fan, "The impact of temperature on gaming productivity: evidence from online games," Empirical Economics, vol. 58, no. 2, pp. 835-867, Feb. 2020, doi: 10.1007/s00181-018-1523-7.

[41] R. Fishman, P. Carrillo, and J. Russ, "Long-term impacts of exposure to high temperatures on human capital and economic productivity," Journal of Environmental Economics and Management, vol. 93, pp. 221-238, Jan. 2019, doi: 10.1016/j.jeem.2018.10.001.

[42] E. Yamamura, "Do You Want Sustainable Olympics? Environment, Disaster, Gender, and the 2020 Tokyo Olympics," Sustainability, vol. 13, no. 22, p. 12879, Nov. 2021, doi: $10.3390 /$ su132212879. 